\section{Europe reconsidering DTCA}

$\mathrm{F}$ ive international associations have joined forces to oppose an anticipated move by the European Commission that would give pharmaceutical companies more freedom to communicate directly with the public.

In its declaration, Relevant Health Information for Empowered Citizens, the alliance claims that pharmaceutical companies have an inherent conflict of interest that renders them unable to provide the information patients need in an unbiased manner. The alliance brings together Health Action International (HAI), the International Society of Drug Bulletins, the European Consumers' Organization, the Medicines in Europe Forum and the Association Internationale de la Mutualité.

Although proposals to relax the rules preventing direct-to-consumer advertising (DTCA) were overwhelmingly rejected by the European Parliament in 2004, HAI's European Campaigns Coordinator Teresa Alves says alliance members are convinced that the European Commission is preparing the way for new legislation to allow advertising disguised as direct-to-consumer information.

HAI points to the formation of the European Commission's Pharmaceutical Forum as evidence of political maneuvers at the highest level to develop the proposals. The Forum, which was established in 2005, is chaired by European Commission Vice-President Günter Verheugen and is dominated by industry representatives. One of the forum's key tasks is to draft recommendations to improve patient access to drug information. In his speech to the Forum in September 2006, Verheugen, who is also responsible for enterprise and industry within the Commission, said he regretted that the Commission's last attempt to reform the rules that prevent industry from communicating with the public had failed in 2004.

The debate about giving companies the power to communicate with the public is likely to focus on the distinction between advertising and information. The European Federation of Phar- maceutical Industries \& Associations rejects the view that companies are unable to provide unbiased information because they have a conflict of interest. "It is simply wrong to assume that all information coming from companies is promotional by nature," it stated, highlighting data on managing side effects and information on mode of action as examples.

The Federation's Communications Manager Christophe de Callatay says they are also arguing for a legal framework that would allow companies across Europe to conduct "disease awareness campaigns" and other educational activities, and is pursuing that agenda within the Pharmaceutical Forum.

The European Commission's Pharmaceutical Forum is slated to present its final recommendations on patient access to information in June. - Colin Meek, Wester Ross, Scotland

DOI:IO.I503/cmaj.070483

\section{New Brunswick medical}

\section{school expansion delayed}

A medical education training program scheduled to start in New Brunswick in September 2008 will be delayed by at least I year, according to Dalhousie University's dean of medicine.

Dr. Harold Cook says the New Brunswick government still hasn't accepted a 30 -seat proposal that was submitted by the Halifax-based university in June 2006. Once an agreement is reached, it will take 2 years to get the program up and running.

New Brunswick Health Minister Michael Murphy has pledged "decisive action" on the file "very soon," but stressed he cannot speak for cabinet. The government remains committed to the project, he says.

Murphy has been working on the medical education training program with the department of Post-Secondary Education and Training almost daily since taking over the health portfolio last fall. It's a complex project, involving 4 Anglophone regions: Saint John,
Moncton South-East, Fredericton and Miramichi, he said.

Dealing with the planned resignations of I4 of the Saint John Regional Hospital's I7 emergency doctors last January also took up a lot of time, said Murphy.

Former premier Bernard Lord had set September 2007 as the initial startup for the program. That was bumped to 2008 under Premier Shawn Graham.

Although details about the proposed program are scarce, it's expected students will spend most of their first 2 academic years in Saint John, while their third and fourth years will involve clinical rotations at hospitals in the $4 \mathrm{An}$ glophone regions.

Having a New Brunswick-based program is expected to help the province recruit and retain doctors.

The provincial government is expected to pay Dalhousie $\$ 55$ ooo per student per year, the same price the Nova Scotia government is paying the university to train doctors. That's \$I.65 million a year, or about $\$ 6.6$ million over 4 years for I graduating class.

In addition, there will be infrastructure costs to accommodate the program at the University of New Brunswick Saint John campus.

Memorial University in Newfoundland was involved in initial discussions about the Anglophone program with the province and Dalhousie, but dropped out in March 2006. The plan to combine the schools required too heavy a financial commitment and the logistics were too complicated, according to Dean of Medicine Dr. James Rourke.

The idea of an Anglophone medical training program was raised after officials at the Université de Moncton and Université de Sherbrooke presented a proposal for a 24-seat French-language medical training program to be based in Moncton.

Under the Centre du formation medical du Nouveau-Brunswick, which started last fall, Sherbrooke students finish their third year in New Brunswick and stay in the province for their fourth year and 2 years of internships. - Bobbie-Jean MacKinnon, Saint John, NB

DOI:Io.I503/cmaj.070485 